\title{
The Alliance-Outcome Association in the Treatment of Adolescent Depression.
}

\section{Authors:}

Antonella Cirasola $^{1,2} *$, Nick Midgley ${ }^{1,2}$, Peter Fonagy ${ }^{1,3}$, IMPACT Consortium ${ }^{4}$, and Peter $\operatorname{Martin}^{2,5}$

${ }^{1}$ Research Department of Clinical, Educational and Health Psychology, University College London, London, $U K$

${ }^{2}$ Child Attachment and Psychological Therapies Research Unit (ChAPTRe), Anna Freud National Centre for Children and Families, London, UK

${ }^{3}$ Anna Freud National Centre for Children and Families, London, UK

${ }^{4}$ Department of Psychiatry, University of Cambridge, Cambridge, UK

${ }^{5}$ Department of Applied Health Research, University College London, London, UK

*Corresponding author: Antonella Cirasola; Email: Antonella.cirasola@annafreud.org; Postal address: Anna Freud National Centre for Children and Families 4-8 Rodney Street London N1 9JH

Acknowledgements: We thank all the young people and therapists who took part in this research.

Funding: The IMPACT study was funded by the National Institute for Health Research (NIHR) Health Technology Assessment (HTA) programme (project number 06/05/01). The views expressed in this publication are those of the authors and do not necessarily reflect those of the NIHR. This research was supported by a PhD grant to the first author by the British Association of Counselling and Psychotherapy (BACP).

Disclosure of interest: The authors declare no conflict of interest. 
Members of the IMPACT Consortium are: Ian MGoodyer, Shirley Reynolds, Barbara Barrett, Sarah Byford, Bernadka Dubicka, Jonathan Hill, Fiona Holland, Raphael Kelvin, Nick Midgley, Chris Roberts, Rob Senior, Mary Target, Barry Widmer, Paul Wilkinson, and Peter Fonagy. 


\title{
The Alliance-Outcome Association in the Treatment of Adolescent Depression
}

\begin{abstract}
A growing body of research has consistently demonstrated a relationship between alliance and treatment outcomes in youth psychotherapy. However, past research often suffered methodological issues that prevented detailed investigation of temporal relationships between alliance and symptomatology. The current study explored the directions of effect between alliance and outcome by examining the associations between early alliance and subsequent outcome while controlling for patients' baseline severity and prior symptom change. It also examined potential moderators of this association. Data were drawn from the IMPACT study, a randomized controlled trial comparing cognitive-behavioural therapy (CBT) and short-term psychoanalytic psychotherapy (STPP) versus a brief psychosocial intervention (BPI) in the treatment of adolescent depression. Adolescents $(\mathrm{N}=224)$ and therapist $(n=139)$ rated the alliance 6 weeks after randomization. Depression severity and overall psychopathology were assessed at baseline, 6, 12, 36, 52 and 86 weeks after randomization. Patients' age, gender, baseline depression severity, conduct disorder symptoms and treatment type were examined as potential moderators of the alliance-outcome association. Data were analysed using multilevel models. Findings suggested that higher early alliance ratings were associated with subsequent symptom reduction, even after controlling for prior symptom change and baseline severity. There was evidence that the strength of this association was strongest in CBT patients, weaker in STPP, and statistically indistinguishable from zero in BPI. These findings suggest that early therapeutic alliance with adolescents may influence subsequent outcome independent of prior symptom change and initial severity but that the effect of the alliance on outcome might vary across treatment types.
\end{abstract}

Keywords: alliance, prior symptom change, $\mathrm{p}$ factor, depression, youth psychotherapy 


\section{Research Background}

Despite the increasing understanding that talking therapies are effective treatments for adolescents' mental health issues (Cuijpers et al., 2020; National Institute for Health and Clinical Excellence (NICE), 2005), little is known about what makes psychotherapy work. As different interventions have often shown similar effects (Cuijpers et al., 2008; Goodyer et al., 2017a), it is important to understand whether there are shared features of effective therapies which contribute to their success, despite apparent differences in therapeutic technique and underlying theory. One of the most promising directions of research concerns the therapeutic alliance, commonly described as the agreement between patient and therapist on therapy goals and tasks, in the context of an emotional bond (Bordin, 1979). A growing body of research has consistently demonstrated a moderate association between good alliance and positive outcome in adult psychotherapy (Flückiger et al., 2018) and a weak association in youth psychotherapy (Karver et al., 2018; Shirk et al., 2011a). These findings appear to suggest that the alliance is a core element of all effective psychological therapies (Norcross, 2011).

Despite the consistent evidence of an association between alliance and outcomes, the role of the alliance has been questioned in recent years, especially in youth psychotherapy (McLeod, 2011). This is not only because the alliance explained a small proportion of the variance in clinical outcomes, but also because of the methodological issues around the estimation of the alliance-outcome relationship. As the alliance is the product of the interaction between patent and therapist, it cannot be manipulated experimentally and randomly assigned to a select group of therapists-client dyads. It is therefore difficult to provide compelling causal evidence for its role as a mechanism of change (Crits-Christoph et al., 2011). Only indirect evidence can be used to support the possibility of a causal relation between alliance and treatment outcome. While in adult psychotherapy sophisticated methods have been used to better study the direction of the relationship between alliance and outcomes, this is not the case 
in youth psychotherapy. Despite its recent growth, youth alliance research still lags behind the adult literature and presents several methodological limitations.

To date six meta-analytic reviews have been conducted on the alliance-outcome relationship in youth psychotherapy. Their findings have consistently demonstrated a weak to medium association between alliance and outcomes ranging from 0.14 to 0.29 (Karver et al., 2006, 2018; McLeod, 2011; Shirk et al., 2011b; Shirk \& Karver, 2003). However, these reviews, especially the earlier ones, present several methodological limitations and need to be interpreted with caution. First, they all include a limited number of studies (raging from 9 to 28). Second, two of these meta-analyses did not focus directly on the alliance but included a wider set of relationship variables (i.e. treatment involvement, therapeutic responsiveness, therapist empathy etc.) (Shirk, \& Karver, 2003; Karver, et al. 2006); hence their findings might or might not be ascribable to the alliance. Third, most meta-analyses included different types of therapy (i.e. child-, parent-, and family-focused interventions) and the alliance might function differently in family therapy than in individual therapy (Karver et al., 2006; Murphy \& Hutton, 2018; Shirk \& Karver, 2003). Furthermore, in most meta-analyses alliance ratings were not required to be administered before outcome measures (Karver et al., 2006; Murphy \& Hutton, 2018; Shirk \& Karver, 2003). Measurement of relationship variables late in therapy might be confounded with outcomes and therefore be biased by concurrent perception of progress. Besides, given the large variability within the studies included in meta-analytic reviews, it is important to consider the impact of methodological challenges and other variables on the estimated alliance-outcome association.

\section{Temporal Relationships between Alliance and Symptomatic Change}

The most noteworthy challenge to the interpretation of the alliance-outcome association refers to the impact of temporal confounds and early treatment gains (Strunk et al., 2010). Most alliance research has examined the relation between alliance assessed at some specific time- 
point and outcome measured at posttreatment. Further, in youth psychotherapy the majority of studies assessed alliance and outcome concurrently rather than prospectively (McLeod, 2011; Simpson, Frick, Kahnx, \& Evans, 2013). Although this type of design highlights covariation of alliance and (sometimes distal) outcome, such studies in themselves cannot establish whether the alliance has a causal effect on treatment outcome. Owen and colleagues (2016) attempted to address some of these limitations by testing the association between alliance and outcome using different models to assess this relationship. They found that changes in alliance scores were more predictive of outcome than single or aggregated alliance scores (Owen et al., 2016).

Yet, even results from research with prospective designs are not sufficient to prove the role of alliance as a change mechanism in psychotherapy, given the potential confound of prior symptom change (Shirk et al., 2010). Substantial change in psychotherapy often occurs within the first few sessions of treatment (Crits-Christoph et al., 2001; Haas et al., 2002; Hegarty et al., 2019). Further, early changes are known to be reliable predictors of treatment outcome (Cromley \& Lavigne, 2008) and are often followed by increases in therapeutic alliance (CritsChristoph et al., 2006; Tang \& DeRubeis, 1999). In other words, it is possible that change in psychotherapy drives the quality of the therapeutic alliance rather than the alliance being responsible for therapeutic change. To establish that alliance quality promotes improvement, and is not simply a by-product of it, researchers have called for more stringent analyses that employ greater statistical control over prior improvement (Falkenström et al., 2013; ZilchaMano et al., 2014). One method for dealing with this is to examine early alliance ratings as a predictor of subsequent change on outcome while controlling for change in outcome that occurred prior to the point at which the alliance was measured.

In youth psychotherapy, only a handful of studies has controlled for pre-treatment symptom severity or prior symptom change in the estimation of the alliance-outcome 
association. The few studies that controlled for initial severity found evidence for an association between early alliance and subsequent improvement at mid-treatment in cognitivebehavioural therapy (CBT) for young people with depression (Labouliere, Reyes, Shirk, \& Karver, 2017) and anxiety disorders (Chiu et al., 2009). The empirical evidence on the allianceoutcome relationship while controlling for prior symptom change is scant and present mixed results. Reyes and colleagues (2014) found a relationship between alliance and subsequent symptom improvement even after controlling for prior symptom change in modified CBT or treatment as usual for adolescents with depression and interpersonal trauma (Reyes, 2014). However, in a previous study, not only did observed alliance not predict subsequent change, it failed to predict symptom change without controlling for early change in CBT for adolescent depression (Reyes, 2008).

\section{Moderators of the Alliance-Outcome Association in Youth Psychotherapy}

Differently from the adult literature, in youth psychotherapy the alliance-outcome relationship revealed to be moderated by a variety of factors, including adolescents' demographic characteristics, type of problem, and type of treatment (Karver et al., 2018; McLeod, 2011). Specifically, being female and younger were found to be associated with a stronger alliance-outcome relationship (Accurso \& Garland, 2015; McLeod, 2011; Shirk et al., 2011b). This might suggest that the alliance is more instrumental in achieving change for younger and female patients than their older and male counterpart.

With regards to symptom severity, some have found that higher baseline symptoms severity predicted higher alliance (Chu et al., 2014), but less is known on whether this might, in turn, affect the alliance-outcome relationship. Additionally, the association between alliance and outcomes was found to be stronger when outcome was global psychopathology/functioning rather than specific symptoms (McLeod, 2011). This finding could suggest that the alliance promotes change at a more broad-spectrum level. This is 
especially relevant since in recent years there has been a move towards a transdiagnostic understanding of metal heath issues in terms of general psychopathology -sometimes labelled the $\mathrm{p}$ factor- rather than specific symptoms (Aitken et al., 2020; Constantinou et al., 2019).

The strength of the alliance-outcome relation with youths also varied according to their presenting problem and was found to be stronger for externalizing samples than for internalizing samples (Shirk and Kraver, 2003; McLeod, 2011; Shirk et al, 2011; Karver, et al., 2018). This might suggest that because of the greater challenge in engaging oppositional and disruptive youths, the alliance has a key role in promoting change with these population.

Treatment type also emerged as a possible moderator variable of the alliance-outcome association in youth psychotherapy, with stronger associations in behavioural versus nonbehavioral therapies (Shirk et al., 2011; Karver et al., 2018). Based on these findings it could be argued that the role of the alliance differs across therapy types. For instance, some therapies might consider the alliance as a pre-condition for change, while others as a mechanism for change (Horvath, 2018).

Another factor to consider in the examination of an alliance-outcome relationship is the reporter. In youth psychotherapy, the association between alliance and outcomes was found to be stronger when the alliance was rated by therapists or parents than when assessed by young patients (Shirk \& Karver, 2003; McLeod, 2011; Karver et al, 2018).

Overall, the literature on moderators of the alliance-outcome association in youth psychotherapy seems to suggest the existence of differences in its strength depending on some patients' baseline characteristics and the type of treatment delivered. Focusing on moderators in various evidence-based treatments is important in future research to address the vital question of for whom the alliance is more or less important for the success of treatment.

\section{The Present Study}


The current study aimed to move beyond merely estimating the magnitude of the alliance-outcome relationship by controlling for prior symptom change and baseline severity and by exploring potential moderators of this relationship. The specific aims of this study were: (1) to investigate the relationship between early alliance and subsequent change in depression while controlling for the effect of prior symptom change and baseline symptom severity among depressed adolescents who received one of three types of short-term psychological therapy; (2) to examine whether this association differs as a function of patient characteristics (sex, age, baseline symptom severity, conduct problems) or type of therapy. We also explored whether the strength of the alliance-outcome association differed based on whether the alliance was rated by adolescent or therapist and whether outcome was assesses via measuring specific symptoms (depression severity) or overall psychopathology (p factor).

Based on existing evidence, we hypothesised that:

1. Higher alliance ratings will be associated with subsequent decreases in depressive symptoms even after controlling for both prior symptom change and baseline symptom severity.

2. This association would be higher for adolescents who

a) were younger and female

b) reported greater baseline symptom severity

c) showed more conduct problems

d) who attended cognitive-behavioural therapy or brief psychosocial intervention rather than short-term psychoanalytic psychotherapy.

\section{Method}

Data were obtained from the the Improving Mood with Psychoanalytic and Cognitive Therapies (IMPACT) trial, a multicentre, pragmatic, randomised controlled trial (RCT) assessing the medium-term effects of three therapeutic interventions in the treatment of 
adolescent depression (Goodyer et al., 2017, 2011). 465 adolescents (aged between 11 and 17 years) with diagnosis of depression were randomised to receive either cognitive behavioural therapy (CBT), short-term psychoanalytic psychotherapy (STPP) or brief psychosocial intervention (BPI). Full details of the method and procedure of the IMPACT study are reported in in Goodyer and colleagues $(2011,2017)$. The present study included only all participants who received treatment and had at rating of the alliance early in treatment.

\section{Ethical considerations}

The study protocol was approved by a UK National Health Service ethics committee. Fully informed written consent was obtained from participants, or parents for those under the age of 16 .

\section{Measures}

\section{Outcomes}

In line with the IMPACT study, the primary outcome was self-reported depression symptoms, our secondary outcome was general psychopathology. Outcome assessments took place at baseline and after randomization at 6 and 12 weeks (during treatment), as well as 36 weeks (completed treatment for $>70 \%$ ) and 52 and 86 weeks (after treatment follow-ups).

Depression Severity. Depression symptoms was assessed with the Mood and Feelings Questionnaire (MFQ) (Angold et al., 1987). The MFQ is a 33-item self-report measure of depressive symptoms, it consists of a series of descriptive phrases regarding how the participant has been feeling or behaving over the past two-week period. Total scores range from 0 to 66 , with higher scores reflecting higher depression severity. It has demonstrated good test-retest reliability over a two- to three-week period (Pearson's $r=0.78$ ), good internal consistency (Cronbach's $\alpha=0.82)$ and discriminant validity $(\alpha=0.89)$ for detecting an episode of depression in adolescents (Kent et al., 1997; Wood et al., 1995). The MFQ also showed good construct validity as it is highly correlated with the Children's Depression Inventory $(r=0.7)$ (Sund et 
al., 2001). In our sample the internal consistency was similarly high (Cronbach's $\alpha=0.93$ ). The clinical cut-off for the presence of a major depressive episode is 27 (Wood et al., 1995).

General psychopathology (p factor). The p factor is a concept popularised by Caspi et al. (2014) that represents a dimension of General Psychopathology measured by a wide spectrum of mental health symptoms. It is an empirically derived latent variable of general psychopathology based on a bi-factor analysis using measures assessing a wide range of symptoms domains including melancholic features, depressive cognitions, anxiety, obsessioncompulsion and conduct problems (Smith et al., 2020). In the IMPACT trial the p factor was calculated using the following 5 measures (a) the Mood and Feelings Questionnaire (Angold et al., 1987), a 33-item measure of depression symptoms; (b) the Revised Children's Manifest Anxiety Scale (Reynolds \& Paget, 1981), a 28-item anxiety questionnaire; (c) the short Leyton Obsessional Inventory (Bamber et al., 2002), an 11-item measure of obsessions and compulsions; and (d) an 11-item antisocial behaviour checklist derived from DSM-IV criteria for conduct disorder (Goodyer et al., 2011). Hence, it contains variance from all psychopathology items of the measures included (examples of items are: 'I feel miserable or unhappy', 'I worry a lot of the time', 'I get mad easily', 'I talk or move to avoid bad luck'). More details about the measures used and the methodology to estimate the $\mathrm{p}$ factor in the IMPACT study are reported elsewhere (Aitken et al., 2020; Fiornini et al., n.d.). Research in clinic and community samples have supported the reliability and validity of the general psychopathology factor (Constantinou etal., 2019; Carragher et al., 2016; Haltigan et al., 2018; Patalay et al., 2015). In our sample, the internal consistency of all the items used for the estimation of the $\mathrm{p}$ factor was high (Cronbach's $\alpha=0.96)$.

\section{Alliance}


The Working Alliance Inventory short form (WAI-S) (Horvath \& Greenberg, 1989; Tracey \& Kokotovic, 1989) aims to measure Bordin's (1979) conceptualization of the working alliance. Accordingly, it includes three 4-item subscales assessing: (a) agreement on Goals, (b) agreement on Tasks and (c) the emotional Bond between patient and therapist. Items are rated on a 7-point scale (from $1=$ Never to $7=A l w a y s$ ). The scale yields different ratings for each subscale as well as an aggregate overall rating ranging from 12 to 84 with higher ratings reflecting a stronger alliance. Due to the lack of empirical evidence for the differentiation between subscales (Cirasola et al., 2020; Marcus et al., 2011) only the overall score was used in this study. The WAI-S has demonstrated good construct validity with other therapeutic alliance measures (ranging between $r=0.74$ and $r=0.80$ ) (Horvath \& Greenberg, 1989; Tracey $\&$ Kokotovic, 1989) and internal consistency in both adult (Cronbach's $\alpha=0.93$ ) (Horvath \& Greenberg, 1989) and youth samples (Cronbach's $\alpha=0.94)$ (Capaldi et al., 2016). In our sample the internal consistency was high for both the adolescent (WAI-S) and therapist (WAI-S-T) reported version of the scale (Cronbach's $\alpha=0.95)$.

Both WAI-S and WAI-S-T were collected at 6 weeks post-randomisation (within the first 4 sessions of treatment). This time point was pre-scheduled after randomization and do not necessarily correspond to the same number of sessions for all participants. Information about how many sessions had been attended at 6 weeks after randomization was not available.

\section{Moderators}

Demographics. Age and gender were assessed with a questionnaire at baseline.

\section{Baseline symptom severity.}

Depression. MFQ described above.

General psychopathology. P factor described above.

Baseline conduct problems. The Antisocial Behaviours Questionnaire (ABQ) (Goodyer et al., 2017a) is a self-report, 11-item checklist for symptoms of antisocial behaviour, 
based on the DSM-IV (American Psychiatric Association (APA), 1994) criteria for conduct disorder. Scores range from 0 to 22 , with higher scores reflecting more severe antisocial behaviours. It has been demonstrated to have adequate reliability and validity for assessing delinquency and antisocial conduct in adolescents in previous studies (Cronbach's $\alpha=0.78$ ) (Cousins et al., 2016; St Clair et al., 2017). In our sample the internal consistency was also good (Cronbach's $\alpha=0.79)$.

\section{Treatment Conditions}

Adolescents in the study were randomised to receive one of the following three treatments.

Cognitive Behavioural Therapy (CBT) focused on identifying the behaviours and the cognitive biases that maintain the depressive symptoms and aimed to amend these biases, through a process of collaborative empiricism between the therapist and patient. Sessions focused on working on explicit, tangible and shared goals (IMPACT Study CBT Sub-Group., 2010). The planned duration was up to 20 sessions delivered over 28 weeks.

Short Term Psychoanalytic Psychotherapy (STPP) aimed to promote better selfunderstanding of feelings and difficulties and to address the underlying dynamics of the symptoms, not only the symptoms per se (Cregeen et al., 2016). STPP therapists focused on a close observation of the therapeutic relationship and used supportive and expressive strategies to address difficulties in the context of the developmental tasks of adolescence. The planned duration was 28 weekly sessions.

Brief Psychosocial Intervention (BPI) is a generic, goal-oriented treatment focused on psychoeducation about depression, problem solving, and encouraging increasing positive activities (Kelvin et al., 2010). BPI was not designed to focus on self-understanding nor on changes in cognitions per se. This psychiatry-led approach emerged from the treatment as usual in in the Adolescent Depression Antidepressants and Psychotherapy Trial (Wilkinson et al., 2011). The planned duration was up to 12 sessions delivered over 20 weeks. 
Although the three treatments differed in planned number of sessions offered, the actual length of treatment was equivalent across groups (Goodyer et al., 2017). All treatments were manualised and demonstrated to be delivered with fidelity to their respective treatment approach (Goodyer et al., 2017b, 2017a; Midgley et al., 2018).

Therapists in the IMPACT study were drawn from CAMHS clinics: CBT therapists were either experienced clinical psychologists or had a professional qualification in CBT; STPP therapists were trained and had professional qualification in child and adolescent psychoanalytical psychotherapy; and the majority of BPI therapists were child psychiatrists.

\section{Participants}

WAI-S sample. This sample consisted of 223 adolescents, i.e. all participants who completed the WAI-S at 6 weeks after randomization and started treatment.

WAI-S-T sample. This sample consisted of 139 adolescents, i.e. all participants who had therapists' ratings of the WAI-S at 6 weeks after randomization and had started treatment.

Both subsamples showed comparable characteristics to the overall IMPACT sample in relation to baseline characteristics, symptom severity, outcome and treatment length (see Table $\mathrm{S} 1$ in the Supplementary material). Samples descriptive are displayed in Table 1. Similar to the overall IMPACT sample, across treatment arms in both subsamples the differences in patients baseline demographic characteristic and symptom severity were small and statistically not significant (see Table 1).

[Table 1 near here]

\section{Analytical strategy}

We analysed the data using multilevel modeling (MLM) with the "nlme" package (Pinheiro et al., 2019) of the R software (R Core Team, 2018). First, we estimated prior symptom change and baseline symptom severity, then assessed the early alliance-outcome association with and without controlling for these two variables for both outcomes considered. 
Subsequently we investigated evidence for moderation effects on the early alliance-outcome association for the primary outcome only. Details of the analyses performed are reported below.

\section{Estimation of prior symptom change and baseline symptom severity}

We fit a 3-level model with repeated outcomes measures (i.e. within-patient differences) at level 1, nested within participants (i.e. between-patient differences) at level 2, who in turn were nested within therapists (level 3). We allowed for random intercepts for participants and therapists, and random slopes for participants. This model included outcomes from the baseline and 6-weeks assessments as dependent variable and time as predictor. Separate models were estimated for MFQ (depression severity) and the p-factor (general psychopathology). MLM accounts for data dependency in repeated measurement; therefore, it provides more accurate estimates of each participant's prior symptom change and baseline symptoms severity. Best linear unbiased predictions (BLUP) of both a) the participant-specific intercept and b) the participant-specific slope were used in the analyses of the alliance outcome association outlined below. Using these model-based estimates of baseline severity and early symptom change, rather than using observed values without modelling, has the advantage of accounting for regression to the mean.

\section{Alliance-outcome association}

To investigate the alliance-outcome association, we fit a 3-level model with outcomes subsequent to the alliance measurement (e.g. MFQ and p factor from week 12 to week 86, in separate models) as the dependent variable, and early alliance (as assessed by the WAI-S at 6 weeks), type of treatment, and time as predictors. This model (Model 0) assessed the unadjusted relationship between alliance and subsequent outcome. To address our primary research question, a separate model (Model 1) additionally controlled for model-based estimates of baseline severity and early symptom change, obtained as outlined above. In both 
models, we allowed the intercept (depression severity at 12 weeks) to vary randomly between adolescents and therapists and used an unstructured covariance matrix for correlations between random effects. Participant-level random slopes for the time variable were also included to allow for variation in the rate of symptom change between adolescents. Time was logtransformed in our analyses, in line with previous research on the same data, which demonstrated that mean outcome scores did not change linearly over time, but could be modelled using a logarithmic time variable (e.g. the rate of improvement slows as time goes by) (O'Keeffe et al., 2019). This was also confirmed in our samples where the logarithmic model fitted the data better than the linear model for both outcome variables (see Table S2 in the Supplementary material).

\section{Alliance- rate of outcome change association}

To assess whether the average outcome rate of change over time was dependent on the alliance, we also investigated a two-way interaction between time and alliance (Model 2) and assessed whether this led to an improvement in model fit compared to Model 1.

\section{Effect size}

We generally report unstandardised slope estimates, but we also derived a standardised measure of the effect of the alliance on outcome by standardising both the WAI-S score and the outcome and re-running the analyses to estimate the standardised coefficient of the allianceoutcome relationship in each model (Beta). The WAI-S score was standardised by subtracting the mean and dividing it by the standard deviation, the MFQ and p factor score from 12 to 36 weeks was standardised by dividing each score by the baseline standard deviation.

\section{Moderation Analyses for the primary outcome (MFQ)}

The effect of moderators on the alliance-outcome relationship was tested by examining in separate models subsequent depression change as a function of each alliance by moderator interaction, while controlling for prior change, baseline severity and treatment arm. We 
centered all continuous moderators at their grand mean. Alliance and outcome were both standardised in these analyses.

As treatment arm was already a predictor in the main model, for this moderator we also compared the model including treatment arm as an independent predictor (Model 1) with an equivalent model that included the interaction between alliance and treatment arm to assess whether adding the interaction improved model fit.

\section{Model comparison}

For all model comparisons we used the Akaike's Information Criterion (AIC) and Bayesian Information Criterion (BIC) and the likelihood ratio (LR) tests. Information criteria are indicators of model quality that take account of both model fit and model complexity, by penalising larger models. Smaller AIC and BIC indicate a better model.

The same sets of analysis were conducted using the adolescents' (WAI-S) and therapists' (WAI-S-T) ratings of the alliance, separately.

\section{Missing data}

There were no missing data for our predictor and moderator variables. With regards to the outcome variables (MFQ and p factor from 12 to 86 weeks), missing data-point increased in the later assessment times (see Table 2), likely due to research attrition and questionnaire fatigue. Little's missing completely at random (MCAR) test suggested that there was little evidence against the MCAR assumption (WAI-S sample: Chi-Square $=30.18, \mathrm{p}=0.279$; WAIS sample: Chi-Square $=23.98, \mathrm{p}=0.632$ ). Accordingly, we handled missing data using MLM (Rubin, 1987). MLM takes into account information from all individuals in the sample when calculating parameter estimates, retaining patients in the longitudinal analysis who had at least one MFQ score from week 12 to posttreatment).

\section{Results}

Descriptive statistics for all variables in both samples are displayed in Table 2. 
[Table 2 near here]

\section{Alliance-Outcome Association Controlling for Prior Change and baseline symptom severity}

We found no evidence that the logarithmic rate of change in outcome over time was influenced by the alliance. As shown in Table S3 in the Supplementary material, the model using alliance and time as independent predictors of outcomes, while controlling for prior symptom change, baseline severity and treatment condition, (Model 1) showed lower estimates in both the AIC and BIC indices compared to the equivalent model including the interaction between alliance and time (Model 2). This was the case for both outcomes as well as for adolescents and therapists' ratings of the alliance. Therefore, we report the results of the model using alliance and time as independent predictors of subsequent outcome.

[Table 3 near here]

Table 3 shows the results of the model assessing the early alliance-outcome association in the WAI-S sample for both the primary outcome (MFQ-rated depression change) and overall psychopathology (p factor) with (Model 1) and without (Model 0) controlling for prior symptom change and baseline severity. When not controlling for baseline symptoms and prior symptom change (Model 0), we found moderate associations between the early alliance and outcome with an effect size of -0.39 for the MFQ and of -0.36 for the $p$ factor. As per our first hypothesis, the early alliance-outcome association was statistically significant even after controlling for baseline symptoms and prior symptom change. Yet, the effect size of the alliance-outcome association was lower compared to the simpler model: Beta=- 0.14 for the MFQ and Beta $=-0.20$ for the $\mathrm{p}$ factor.

[Table 4 near here]

Similar results were found in the WAI-S-T sample (see Table 4). The effect sizes of the alliance-outcome associations were found to be stronger in the simpler model (Model 0: Beta=- 
0.30 for the MFQ and Beta=-0.19) than in the model where prior symptom change and baseline severity were controlled for in the analyses (Model 1: Beta=-0.24 for the MFQ and Beta=-0.14 for the $\mathrm{p}$ factor).

\section{Moderators of the Alliance-Primary Outcome Association}

Table 5 shows the estimates of the treatment by moderator effect for each of the five moderators hypothesised. In both samples, there was no evidence of moderation for any of the four patient baseline characteristics considered (age, gender, baseline symptom severity or conduct problems). Hence, in contrast with our hypotheses, these characteristics did not moderate the effect of the alliance on subsequent depression when the alliance was measured by either adolescents or therapists.

[Table 5 near here]

Treatment arm demonstrated to be the only significant moderator of the allianceoutcome association in both samples. As showed in Table S4 in the Supplementary material, the AIC and likelihood ratio test in both samples were lower in the model including the interaction between alliance and treatment compared to Model 1. Although there were small differences in the strength of the alliance-outcome association across treatment arms, there was some evidence that the alliance-outcome association was stronger in CBT than in BPI, and minor, if any, differences between CBT and STPP and STPP and BPI (see Table 5). Accordingly, the early alliance-outcome association was higher in CBT than in STPP and there was little evidence for an alliance-outcome relationship in BPI (see Table 6).

[Table 6 near here]

\section{Discussion}

Despite the consistent findings that therapeutic alliance is positively associated with treatment outcome in both youth and adult psychotherapy (Flückiger et al., 2018; Karver et al., 2018), uncertainty remains about whether good alliance precedes or is a result of early 
symptomatic change. This study examined the relation between early alliance and subsequent symptom change while controlling for prior symptom change and baseline severity in youth psychotherapy for adolescent depression. Additionally, it examined whether some potential baseline patient-level characteristics and treatment type moderated this association.

\section{Alliance Effect on Outcome}

We found evidence that both adolescent and therapist early ratings of the alliance are associated with subsequent symptom change (measured six weeks after the early alliance assessment in our study), controlling for prior symptom change and baseline severity. However, early alliance did not predict the rate of decrease in symptoms over time after this initial impact on symptoms. Hence, while patients who reported greater alliance after six weeks of treatment also subsequently reported better outcomes after twelve weeks, the early alliance did not influence how much depression and general psychopathology symptoms changed over time beyond twelve weeks. This does not mean that the effect of the alliance is short-term. Rather, our findings suggest that any long-term effect of the early alliance on symptoms is mediated by the early alliance's short-term impact.

In this study, after controlling for treatment type, baseline severity and change in outcome occurring before the alliance assessment, the strength of the early alliance-subsequent outcome relationship was significant and ranged between 0.14 and 0.24 . This range depended on whether the alliance was rated by adolescents or therapists and whether the assessment of outcome was specific symptom (depression severity), or overall psychopathology. When prior symptom change and baseline severity were not controlled for in the analyses, the estimated association between early alliance and outcomes were stronger, ranging from 0.18 to 0.39 . This might suggest that the association between alliance and outcome is confounded by early symptomatic improvement. Analyses that do not control for baseline symptom severity and 
prior symptom change may therefore severely overestimate the strength of the allianceoutcome relationship.

Nevertheless, our estimates of the alliance-outcome relationship, even after controlling for prior symptom change and baseline severity, are comparable to the ones found in previous studies and meta-analyses in youth psychotherapy, ranging from .14 to .29 (Shirk \& Karver, 2003; Karver, et a., 2006; Shirk, and Karver, 2011; Shirk, et al., 2011; McLeod, 2011; Karver et al., 2018). However, none of the previous youth alliance research controlled for both prior symptoms change and baseline severity in the assessment of the alliance-outcome relationship. Nevertheless, our findings are in line with a few studies which supported the existence of a relationship between observer-rated alliance and outcome while controlling for baseline symptom severity only (Chiu et al., 2009; Labuliere et al., 2017) or prior symptom change only (Reyes, 2014). In the adult literature, a recent meta-analysis on the relation between alliance and symptoms early in therapy found that in the early phase of therapy, symptoms and alliance were reciprocally related to one other, often resulting in a positive upward spiral of higher alliance/lower symptoms (Flückiger et al., 2020). The findings of our study give preliminary support to the idea that such a pattern may also be found with adolescents. However, given the dearth of research using more stringent analyses in the estimation of the alliance-outcome relationship in youth psychotherapy, more research is needed to confirm our results.

In line with previous research, we also found small differences in the association between alliance and outcome across alliance raters (adolescents vs therapist) and types of outcome (depression vs general psychopathology). In particular, when the alliance was rated by adolescents, the early alliance-outcome association was stronger when outcome assessed general psychopathology than depression. The opposite trend was found from the therapist perspective: therapists' ratings of early alliance were more strongly associated with reduction in subsequent depression than in overall psychopathology. This might suggest that the felt 
experience of alliance, from the young person's perspective, is associated with greater improvement in overall psychopathology rather than the specific symptoms targeted by the treatments. In contrast, the therapist's view of alliance seems more strongly associated with symptom-specific improvement, which may be the domain that therapists are more directly focused on, especially in research trials when they know what the primary outcome is. However, since the differences in the strength of the early alliance-outcome relationship were small and we found mixed results, it is difficult to draw solid conclusion based on our findings. Previous research in youth psychotherapy also found that the alliance-outcome association varied according to the outcome domain assessed, and the rater perspective on the alliance (McLeod, 2011). In this earlier research, overall functioning and therapists' report of the alliance generated larger effects than measures that assessed symptoms and adolescents' reports on the alliance (McLeod, 2011). More attention should be paid to these variables in future research and when aggregating results from different studies.

Overall, our findings suggest that even if small, there is evidence of an effect of adolescents' and therapists' reports of early alliance on outcomes even after controlling for baseline symptoms severity and early change. Considering that adolescents can present with specific challenges to engaging in therapy due to their developmental stage (Everall \& Paulson, 2002), these results might suggest that overcoming these potential barriers and developing a strong therapeutic alliance early in treatment is important for therapeutic outcomes.

\section{Moderators of the Alliance-Subsequent Change Association}

As it has been suggested that the association between early alliance and outcome might be affected by other variables (Kazdin et al., 2006), the second goal of this study was to examine potential moderators of this association. Based on previous literature, adolescents' age, gender, baseline symptom severity and conduct problems were selected as patient related possible moderators. Contrary to our hypotheses, none of these patients' baseline 
characteristics had a statistically significant effect on the alliance-outcome association. This is inconsistent with previous research suggesting that the alliance-outcome link is stronger for female and younger patients (Accurso \& Garland, 2015; McLeod, 2011; Shirk et al., 2011b) and for adolescents who presented more externalising than internalising problems (Shirk and Kraver, 2003; McLeod, 2011; Shirk et al, 2011; Karver, 2018). Our findings are, however, consistent with those in the adult literature where the alliance-outcome relationship resulted independent of a range of patient characteristics (Flückiger, et al., 2018). This might suggest that, when controlling for prior symptom change and baseline symptom severity, the early alliance-outcome association for adolescents follows the same pattern as for adults, and is not significantly influenced by patients' age, gender and symptom severity.

In contrast, treatment arm showed a significant moderator effect on the early allianceoutcome association. This was true for both adolescent and therapist ratings of the alliance. Specifically, CBT demonstrated a stronger early alliance-outcome relationship than STPP. There was no significant association between early alliance and outcome in BPI. This might suggest that early alliance is more instrumental in driving change in CBT than in psychodynamic treatment, while it does not contribute to outcome in BPI. A previous analysis of data from the IMPACT study found significant differences in the average alliance ratings between treatment types, with the alliance being highest in CBT compared to BPI and especially STPP (Cirasola et al., n.d.). Taken together these findings might suggest that not only the strength, but also the role of the alliance, might vary across therapy types, being more responsible for outcome in some therapies than others. It might be that within CBT, where explicit collaboration is an essential part of how technical aspects of the therapy are delivered, the alliance early in treatment has a more significant impact on outcomes. For instance, in youth CBT, early alliance might be essential in promoting active participation and engagement with emotionally challenging tasks that are the hallmark of CBT (Shirk et al., 2008). Although 
collaborative behaviours might occur in other therapies, their frequency, as well as the context in which they arise, might be different to CBT. In psychodynamic therapies, where the allianceoutcome relationship was weaker, while some elements of the early alliance promote better outcome, other therapy specific intervention might be more responsible in driving change. In contrast, in BPI, early alliance did not seem to contribute to outcome, and perhaps other treatment variables such as psychoeducation or goal-oriented activities might be more responsible for change.

The finding that the early alliance-outcome relationship is moderated by treatment type might also be related to the way the alliance has been measured in this study. The WAI-S items, given their emphasis on collaboration of tasks and goals of therapy, might better capture aspects of the alliance that are more in line with the way the alliance is conceptualised and used in CBT than other therapies like STPP or BPI. This would not only influence the apparent (measured) level of the alliance but also its impact on the degree of association with outcome. Additionally, since the alliance was assessed relatively early in therapy, the results of the moderating impact of treatment type on the alliance might be due to the timing of alliance assessment. It could be that the role that the alliance assumes in therapy varies not only across types of therapy but also across stages of therapy.

Our results contribute to the findings of some meta-analyses in youth psychotherapy; which also demonstrated a stronger relationship between alliance and outcome in behavioural treatments versus treatments that included nonbehavioral components (Shirk et al., 2011; Karver et al., 2018). These findings challenge the assumption that the alliance should be important for the success of all therapies. This issue is part of the larger debate on whether the alliance is a generic common ingredient of all therapies acting independently of technique or whether its clinical function - and perhaps meaning- is specific to each type of therapy (Horvath, 2018). Future research should attempt to better understand the role of the alliance 
across types of treatment and provide further insight into the relationship between alliance and outcome within and across types of treatments.

\section{Strengths, Limitations and Future Directions}

The present study has several limitations. First, although we controlled for baseline symptom severity and previous symptom change in an attempt to account for reverse causality between early alliance and symptoms, causality cannot be inferred based on the current findings. Conversely, our method of controlling for early symptom change might result in a downward bias in our estimate of the alliance-outcome association. There could, in fact, be a reciprocal effect between early alliance and early symptom change where better alliance leads to improved symptoms and vice versa. Second, there may be unmeasured confounders that are responsible for the observed association. Since alliance is inherently a relational process, patients' and therapists' interpersonal skills, attachment style, or reflective capacities are also likely to impact on the alliance; thereby affecting the alliance-outcome relationship. Third, in our analyses, the alliance was not rated after a specific session, but at a pre-scheduled timepoint after randomization (approximately 6 weeks) as part of the overall IMPACT trial. A such, the alliance assessment did not happen precisely after the same number of sessions for all participants. Future research should also assess the relationship between changes in working alliance scores over time and outcome as this might provide different estimates (Owen et al., 2016).

This study also has several strengths including being the first study to evaluate the strength of the early alliance-outcome association while controlling for prior symptom change and baseline severity and to assess possible moderators of this relationship using such stringent analyses. Furthermore, data were derived from a randomized controlled trial in which the adherence to treatments was closely monitored for integrity (Goodyer et al., 2017b; Midgley et al., 2018). Other strengths of this study were the inclusion of both adolescents' and 
therapists' ratings of the early alliance and that outcome assessed both specific symptom and overall psychopathology.

\section{Conclusion}

The findings of this study suggest that the strength of the alliance could play a role in determining subsequent treatment outcomes in youth psychotherapy, both in terms of depression and general psychopathology. These outcomes appear to be independent of prior symptom change and initial severity. This provides some support to the assumption that the alliance drives symptom changes rather than being purely the product of prior improvement, at least in CBT and STPP. However, our findings do not preclude the possibility of reciprocal effects between early alliance and symptomatology. While it would be misleading to reduce the alliance to a proxy for improvement, equally the notion of the alliance as a common relationship factor, exerting impact independent of therapeutic progress, may be an oversimplification. We also found evidence the early alliance-outcome relationship was not moderated by adolescents' demographic characteristics and baseline symptom severity, but it was by treatment type. This suggests that the alliance effect on outcome can vary across therapy types; which might question the idea of the alliance as a common, generic factor associated with outcome in all psychological treatments. More research is needed in the field. At the very least, it seems appropriate to challenge the assumption that the alliance represents a general ingredient of all treatments. It might be more beneficial to think of it as a complex process variable that might change across types and stages of therapy.

\section{References}

Accurso, E. C., \& Garland, A. F. (2015). Child, caregiver, and therapist perspectives on therapeutic alliance in usual care child psychotherapy. Psychol Assess, 27(1), 347-352. https://doi.org/10.1037/pas0000031

Aitken, M., Haltigan, J. D., Szatmari, P., Dubicka, B., Fonagy, P., Kelvin, R., Midgley, N., Reynolds, S., Wilkinson, P. O., \& Goodyer, I. M. (2020). Toward precision therapeutics: general and specific factors differentiate symptom change in depressed adolescents. 
Journal of Child Psychology and Psychiatry and Allied Disciplines. https://doi.org/10.1111/jcpp.13194

American Psychiatric Association (APA). (1994). Diagnostic and statistical manual of mental disorders. In American Psychiatric Association. Am Psychiatric Assoc.

Angold, A., Costello, E. J., Pickles, A., Winder, F., \& Silver, D. (1987). The development of a questionnaire for use in epidemiological studies of depression in children and adolescents. London: Medical Research Council Child Psychiatry Unit.

Bamber, D., Tamplin, A., Park, R. J., Kyte, Z. A., \& Goodyer, I. M. (2002). Development of a Short Leyton Obsessional Inventory for Children and Adolescents. Journal of the American Academy of Child and Adolescent Psychiatry, 41(10), 1246-1252. https://doi.org/10.1097/00004583-200210000-00015

Bordin, E. S. (1979). The generalizability of the psychoanalytic concept of the working alliance. Psychotherapy: Theory, Research \& Practice, 16(3), 252-260.

Capaldi, S., Asnaani, A., Zandberg, L. J., Carpenter, J. K., \& Foa, E. B. (2016). Therapeutic Alliance during Prolonged Exposure Versus Client-Centered Therapy for Adolescent Posttraumatic Stress Disorder. Journal of Clinical Psychology, 72(10), 1026-1036.

Carragher, N., Teesson, M., Sunderland, M., Newton, N. C., Krueger, R. F., Conrod, P. J., Barrett, E. L., Champion, K. E., Nair, N. K., \& Slade, T. (2016). The structure of adolescent psychopathology: A symptom-level analysis. Psychological Medicine, 46(5), 981-994. https://doi.org/10.1017/S0033291715002470

Caspi, A., Houts, R. M., Belsky, D. W., Goldman-Mellor, S. J., Harrington, H., Israel, S., Meier, M. H., Ramrakha, S., Shalev, I., \& Poulton, R. (2014). The p factor: one general psychopathology factor in the structure of psychiatric disorders? Clinical Psychological Science, 2(2), 119-137.

Chiu, A. W., McLeod, B. D., Har, K., \& Wood, J. J. (2009). Child-therapist alliance and clinical outcomes in cognitive behavioral therapy for child anxiety disorders. Journal of Child Psychology and Psychiatry and Allied Disciplines, 50(6), 751-758. https://doi.org/10.1111/j.1469-7610.2008.01996.x

Chu, B. C., Skriner, L. C., \& Zandberg, L. J. (2014). Trajectory and Predictors of Alliance in Cognitive Behavioral Therapy for Youth Anxiety. Journal of Clinical Child \& Adolescent Psychology, 43(5), 721-734. https://doi.org/10.1080/15374416.2013.785358

Cirasola, A., Midgley, N., Fonagy, P., Consortium, I., \& Martin, P. (2020). The factor structure of the Working Alliance Inventory short-form in youth psychotherapy : an empirical investigation youth psychotherapy: an empirical investigation. Psychotherapy 
Research, O(0), 1-13. https://doi.org/10.1080/10503307.2020.1765041

Cirasola, A., Midgley, N., Fonagy, P., IMPACT Consortium, \& Martin, P. (n.d.). The therapeutic alliance in psychotherapy for adolescent depression: differences between treatment types and change over time. University College London (UCL).

Constantinou, M. P., Goodyer, I. M., Eisler, I., Butler, S., Kraam, A., Scott, S., FMedSci, Frcp., Pilling, S., Simes, E., Ellison, R., Allison, E., Fonagy, P., Matthew Constantinou, Fm., Stephen Pilling spilling, P., Peter Fonagy, P., \& Stephen Butler, P. (2019). Changes in General and Specific Psychopathology Factors Over A Psychosocial Intervention. Journal of the American Academy of Child \& Adolescent Psychiatry, 58(8), 776-786. https://www.ucl.ac.uk/psychoanalysis/research/systemic-therapy-risk-teens-start

Cousins, L., Whitaker, K. J., Widmer, B., Midgley, N., Byford, S., Dubicka, B., Kelvin, R., Reynolds, S., Roberts, C., \& Holland, F. (2016). Clinical characteristics associated with the prescribing of SSRI medication in adolescents with major unipolar depression. European Child \& Adolescent Psychiatry, 25(12), 1287-1295.

Cregeen, S., Hughes, C., Midgley, N., Rhode, M., \& Rustin, M. (2016). Short-term psychoanalytic psychotherapy for adolescents with depression: A treatment manual. Karnac Books.

Crits-Christoph, P., Connolly, M. B., Gallop, R., Barber, J. P., Tu, X., Gladis, M., \& Siqueland, L. (2001). Early improvement during manual-guided cognitive and dynamic psychotherapies predicts 16-week remission status. The Journal of Psychotherapy Practice and Research, 10(3), 145.

Crits-Christoph, P., Gibbons, M. B. C., Hamilton, J., Ring-Kurtz, S., \& Gallop, R. (2011). The dependability of alliance assessments: The alliance-outcome correlation is larger than you might think. Journal of Consulting and Clinical Psychology, 79(3), 267.

Crits-Christoph, P., Gibbons, M. B. C., \& Hearon, B. (2006). Does the alliance cause good outcome? Recommendations for future research on the alliance. Psychotherapy, 43(3), 280-285. https://doi.org/10.1037/0033-3204.43.3.280

Cromley, T., \& Lavigne, J. V. (2008). Predictors and consequences of early gains in child psychotherapy. Psychotherapy: Theory, Research, Practice, Training, 45(1), 42.

Cuijpers, P., Karyotaki, E., de Wit, L., \& Ebert, D. D. (2020). The effects of fifteen evidencesupported therapies for adult depression: A meta-analytic review. Psychotherapy Research, 30(3), 279-293. https://doi.org/10.1080/10503307.2019.1649732

Cuijpers, P., Van Straten, A., Andersson, G., \& Van Oppen, P. (2008). Psychotherapy for depression in adults: a meta-analysis of comparative outcome studies. Journal of 
Consulting and Clinical Psychology, 76(6), 909.

Everall, R. D., \& Paulson, B. L. (2002). The therapeutic alliance: Adolescent perspectives.

Counselling and Psychotherapy Research, 2(2), 78-87.

https://doi.org/10.1080/14733140212331384857

Falkenström, F., Granström, F., \& Holmqvist, R. (2013). Therapeutic alliance predicts symptomatic improvement session by session. Journal of Counseling Psychology, 60(3), 317-328. https://doi.org/10.1037/a0032258

Fiornini, G., Saunders, R., Fonagy, P., \& Consortium, I. (n.d.). Trajectories of change in general psychopathology levels among depressed adolescents in short-term psychotherapy. University College London (UCL).

Flückiger, C., Del, A. C., Wampold, B. E., \& Horvath, A. O. (2018). The Alliance in Adult Psychotherapy: A Meta-Analytic Synthesis. Psychotherapy, 55(4), 316-340. https://doi.org/10.1037/pst0000172

Flückiger, C., Rubel, J., Liebig, J., Re, A. C. Del, Horvath, A. O., Wampold, B. E., Critschristoph, P., Atzil-slonim, D., Errázuriz, P., Huppert, J. D., Lutz, W., Muran, C. J., Strunk, D. R., Tasca, G. A., Voderholzer, U., Webb, C. A., \& Barber, J. P. (2020). The Reciprocal Relationship Between Alliance and Early Treatment Symptoms : A TwoStage Individual Participant Data Meta-Analysis. 88(9), 829-843.

Goodyer, I. M., Reynolds, S., Barrett, B., Byford, S., Dubicka, B., Hill, J., Holland, F., Kelvin, R., \& Midgley, N. (2016). Cognitive behavioural therapy and short-term psychoanalytical psychotherapy versus a brief psychosocial intervention in adolescents with unipolar major depressive disorder (IMPACT): a multicentre, pragmatic, observerblind, randomised controlled superiori. The Lancet Psychiatry, 0366(16), 1-11. https://doi.org/10.1016/S2215-0366(16)30378-9

Goodyer, I. M., Reynolds, S., Barrett, B., Byford, S., Dubicka, B., Hill, J., Holland, F., Kelvin, R., Midgley, N., Roberts, C., Senior, R., Target, M., Widmer, B., Wilkinson, P., \& Fonagy, P. (2017a). Cognitive-behavioural therapy and short-term psychoanalytic psychotherapy versus brief psychosocial intervention in adolescents with unipolar major depression (IMPACT): A multicentre, pragmatic, observer-blind, randomised controlled trial. Health Technology Assessment, 21(12), 1-93. https://doi.org/10.3310/hta21120

Goodyer, I. M., Reynolds, S., Barrett, B., Byford, S., Dubicka, B., Hill, J., Holland, F., Kelvin, R., Midgley, N., Roberts, C., Senior, R., Target, M., Widmer, B., Wilkinson, P., \& Fonagy, P. (2017b). Cognitive-behavioural therapy and short-term psychoanalytic psychotherapy versus brief psychosocial intervention in adolescents with unipolar major 
depression (IMPACT): A multicentre, pragmatic, observer-blind, randomised controlled trial. Health Technology Assessment, 21(12), 1-93. https://doi.org/10.3310/hta21120

Goodyer, I. M., Tsancheva, S., Byford, S., Dubicka, B., Hill, J., Kelvin, R., Reynolds, S., Roberts, C., Senior, R., Suckling, J., Wilkinson, P., Target, M., \& Fonagy, P. (2011). Improving mood with psychoanalytic and cognitive therapies (IMPACT): A pragmatic effectiveness superiority trial to investigate whether specialised psychological treatment reduces the risk for relapse in adolescents with moderate to severe unipolar depres. Trials, 12(1), 175. https://doi.org/10.1186/1745-6215-12-175

Haas, E., Hill, R. D., Lambert, M. J., \& Morrell, B. (2002). Do early responders to psychotherapy maintain treatment gains? Journal of Clinical Psychology, 58(9), 11571172.

Haltigan, J. D., Aitken, M., Skilling, T., Henderson, J., Hawke, L., Battaglia, M., Strauss, J., Szatmari, P., \& Andrade, B. F. (2018). "P” and "DP:” Examining symptom-level bifactor models of psychopathology and dysregulation in clinically referred children and adolescents. Journal of the American Academy of Child \& Adolescent Psychiatry, 57(6), 384-396.

Hegarty, B. D., Marceau, E. M., Gusset, M., \& Grenyer, B. F. S. (2019). Early treatment response in psychotherapy for depression and personality disorder: links with core conflictual relationship themes. Psychotherapy Research, O(0), 1-12. https://doi.org/10.1080/10503307.2019.1609114

Horvath, A. O. (2018). Research on the alliance: Knowledge in search of a theory. Psychotherapy Research, 28(4), 499-516.

Horvath, A. O., \& Greenberg, L. S. (1989). Development and validation of the Working Alliance Inventory. Journal of Counseling Psychology, 36(2), 233.

IMPACT Study CBT Sub-Group. (2010). Cognitive behaviour therapy for depression in young people: Manual for therapists. http://dev.psychiatry.cam.ac.uk/projects/

Karver, M. S., De Nadai, A. S., Monahan, M., \& Shirk, S. R. (2018). Meta-analysis of the prospective relation between alliance and outcome in child and adolescent psychotherapy. Psychotherapy, 55(4), 341-355. https://doi.org/10.1037/pst0000176

Karver, M. S., Handelsman, J. B., Fields, S., \& Bickman, L. (2006). Meta-analysis of therapeutic relationship variables in youth and family therapy: The evidence for different relationship variables in the child and adolescent treatment outcome literature. Clinical Psychology Review, 26(1), 50-65. https://doi.org/10.1016/j.cpr.2005.09.001 Kazdin, A. E., Whitley, M., \& Marciano, P. L. (2006). Child-therapist and parent-therapist 
alliance and therapeutic change in the treatment of children referred for oppositional, aggressive, and antisocial behavior. Journal of Child Psychology and Psychiatry and Allied Disciplines, 47(5), 436-445. https://doi.org/10.1111/j.1469-7610.2005.01475.x

Kelvin, R. G., Dubicka, B., Wilkinson, P. O., \& Goodyer, I. M. (2010). Brief Psychosocial Intervention (BPI): A specialist clinical care treatment manual for CAMHS use. In Cambridge: University of Cambridge. (Ed.), Cambridge: University of Cambridge (2010).

Kent, L., Vostanis, P., \& Feehan, C. (1997). Detection of major and minor depression in children and adolescents: Evaluation of the mood and feelings questionnaire. Journal of Child Psychology and Psychiatry and Allied Disciplines, 38(5), 565-573. https://doi.org/10.1111/j.1469-7610.1997.tb01543.x

Labouliere, C. D., Reyes, J. P., Shirk, S., \& Karver, M. S. (2017). Therapeutic Alliance With Depressed Adolescents: Predictor or Outcome? Disentangling Temporal Confounds to Understand Early Improvement. Journal of Clinical Child and Adolescent Psychology, 46(4), 600-610. https://doi.org/10.1080/15374416.2015.1041594

Marcus, D. K., Kashy, D. A., Wintersteen, M. B., \& Diamond, G. S. (2011). The therapeutic alliance in adolescent substance abuse treatment: A one-with-many analysis. Journal of Counseling Psychology, 58(3), 449-455. https://doi.org/10.1037/a0023196

McLeod, B. D. (2011). Relation of the alliance with outcomes in youth psychotherapy: A meta-analysis. Clinical Psychology Review, 31(4), 603-616. https://doi.org/10.1016/j.cpr.2011.02.001

Midgley, N., Reynolds, S., Kelvin, R., Loades, M., Calderon, A., Martin, P., O’Keeffe, S., IMPACT Consortium, the I., \& O'Keeffe, S. (2018). Therapists' techniques in the treatment of adolescent depression. Journal of Psychotherapy Integration, 28(4), 413428. https://doi.org/10.1037/int0000119

Murphy, R., \& Hutton, P. (2018). Practitioner Review: Therapist variability, patient-reported therapeutic alliance, and clinical outcomes in adolescents undergoing mental health treatment - a systematic review and meta-analysis. Journal of Child Psychology and Psychiatry and Allied Disciplines, 59(1), 5-19. https://doi.org/10.1111/jcpp.12767

National Institute for Health and Clinical Excellence (NICE). (2005). Depression in Children and Young People: Indentification and Management in Primary, Community and Secondary Care: Quick Reference Guide. NICE.

Norcross, J. C. (2011). Psychotherapy Relationships That Work. Oxford University Press. https://doi.org/10.1093/acprof:oso/9780199737208.001.0001 
O’Keeffe, S., Martin, P., Goodyer, I. M., Kelvin, R., Dubicka, B., Goodyer, I. M., Reynolds, S., Barrett, B., Byford, S., Hill, J., Holland, F., Midgley, N., Roberts, C., Senior, R., Target, M., Widmer, B., Wilkinson, P., \& Fonagy, P. (2019). Prognostic Implications for Adolescents With Depression Who Drop Out of Psychological Treatment During a Randomized Controlled Trial. Journal of the American Academy of Child and Adolescent Psychiatry, 58(10), 983-992. https://doi.org/10.1016/j.jaac.2018.11.019

Owen, J., Miller, S. D., Seidel, J., \& Chow, D. (2016). The working alliance in treatment of military adolescents. Journal of Consulting and Clinical Psychology, 84(3), 200-210. https://doi.org/10.1037/ccp0000035

Patalay, P., Fonagy, P., Deighton, J., Belsky, J., Vostanis, P., \& Wolpert, M. (2015). A general psychopathology factor in early adolescence. British Journal of Psychiatry, 207(1), 15-22. https://doi.org/10.1192/bjp.bp.114.149591

Pinheiro, J., Bades, D., DebRoy, S., Sarkar, D., \& R Core Team. (2019)._nlme: Linear and Nonlinear Mixed Effects Models_. R package version 3.1-140.

R Core Team. (2018). R: A language and environment for statistical computing. $R$ Foundation for Statistical Computing, Vienna, Austria. https://www.r-project.org/

Reyes, J. P. (2008). Therapeutic Alliance, Symptom Change, and Pretreatment Interpersonal Functioning in Cognitive-Behavior Therapy for Adolescents with Depression. University of Denver.

Reyes, J. P. (2014). Examining the alliance-outcome relationship: Reverse causation, third variables, and treatment phase artifacts (Vol. 75) [Available from ProQuest Dissertations \& Theses Global.]. http://search.proquest.com/docview/1493901289?accountid=10226 Rosselló

Reynolds, C. R., \& Paget, K. D. (1981). Factor analysis of the revised Children's Manifest Anxiety Scale for blacks, whites, males, and females with a national normative sample. Journal of Consulting and Clinical Psychology, 49(3), 352.

Rubin, D. B. (1987). Multiple imputation for survey nonresponse. New York: Wiley.

Shirk, S. R., Caporino, N. E., \& Karver, M. S. (2010). The alliance in adolescent therapy: Conceptual, operational, and predictive issues.

Shirk, S. R., Gudmundsen, G., Kaplinski, H. C., \& McMakin, D. L. (2008). Alliance and outcome in cognitive-behavioral therapy for adolescent depression. Journal of Clinical Child and Adolescent Psychology, 37(3), 631-639. https://doi.org/10.1080/15374410802148061

Shirk, S. R., \& Karver, M. S. (2003). Prediction of treatment outcome from relationship 
variables in child and adolescent therapy: A meta-analytic review. Journal of Consulting and Clinical Psychology, 71(3), 452-464. https://doi.org/10.1037/0022-006X.71.3.452

Shirk, S. R., Karver, M. S., \& Brown, R. (2011a). The Alliance in Child and Adolescent Psychotherapy. Psychotherapy, 48(1), 17-24. https://doi.org/10.1037/a0022181

Shirk, S. R., Karver, M. S., \& Brown, R. (2011b). The Alliance in Child and Adolescent Psychotherapy. Psychotherapy, 48(1), 17-24. https://doi.org/10.1037/a0022181

Simpson, T. P., Frick, P. J., Kahn, R. E., \& Evans, L. J. (2013). Therapeutic alliance in justice-involved adolescents undergoing mental health treatment: The role of callousunemotional traits. International Journal of Forensic Mental Health, 12(2), 83-92.

Smith, G. T., Atkinson, E. A., Davis, H. A., Riley, E. N., \& Oltmanns, J. R. (2020). The general factor of psychopathology. Annual Review of Clinical Psychology, 16, 75-98. https://doi.org/10.1017/CBO9781107415324.004

St Clair, M. C., Neufeld, S., Jones, P. B., Fonagy, P., Bullmore, E. T., Dolan, R. J., Moutoussis, M., Toseeb, U., \& Goodyer, I. M. (2017). Characterising the latent structure and organisation of self-reported thoughts, feelings and behaviours in adolescents and young adults. PloS One, 12(4), e0175381.

Strunk, D. R., Brotman, M. A., \& DeRubeis, R. J. (2010). The process of change in cognitive therapy for depression: Predictors of early inter-session symptom gains. Behaviour Research and Therapy, 48(7), 599-606.

Sund, A. M., Larsson, B., \& Wichstrøm, L. (2001). Depressive symptoms among young Norwegian adolescents as measured by the Mood and Feelings Questionnaire (MFQ). European Child \& Adolescent Psychiatry, 10(4), 222-229.

Tang, T. Z., \& DeRubeis, R. J. (1999). Sudden gains and critical sessions in cognitivebehavioral therapy for depression. Journal of Consulting and Clinical Psychology, 67(6), 894.

Tracey, T. J., \& Kokotovic, A. M. (1989). Factor Structure of the Working Alliance Inventory. In Psychological Assessment: A Journal of Consulting and Clinical Psychology (Vol. 1, Issue 3).

Wilkinson, P., Kelvin, R., Roberts, C., Dubicka, B., \& Goodyer, I. (2011). Clinical and psychosocial predictors of suicide attempts and nonsuicidal self-injury in the Adolescent Depression Antidepressants and Psychotherapy Trial (ADAPT). American Journal of Psychiatry, 168(5), 495-501.

Wood, A., Kroll, L., Moore, A., \& Harrington, R. (1995). Properties of the mood and feelings questionnaire in adolescent psychiatric outpatients: a research note. Journal of Child 
Psychology and Psychiatry, 36(2), 327-334.

Zilcha-Mano, S., McCarthy, K. S., Dinger, U., \& Barber, J. P. (2014). To what extent is

alliance affected by transference? An empirical exploration. Psychotherapy, 51(3), 424433. https://doi.org/10.1037/a0036566

Tables:

Table 1. Sample descriptive and comparison across treatment groups

\begin{tabular}{|c|c|c|c|c|c|c|c|c|}
\hline \multicolumn{9}{|c|}{ WAI-S sample $(\mathrm{N}=223)$} \\
\hline & \multicolumn{2}{|c|}{ BPI $(n=72)$} & \multicolumn{2}{|c|}{ CBT $(n=78)$} & \multicolumn{2}{|c|}{$\operatorname{STPP}(n=73)$} & \multirow[b]{2}{*}{ Chi2 } & \multirow[b]{2}{*}{$\mathbf{p}$} \\
\hline & $\mathbf{N}$ & $\%$ & $\mathbf{N}$ & $\%$ & $\mathbf{N}$ & $\%$ & & \\
\hline Gender & & & & & & & 1.03 & 0.597 \\
\hline Male & 18 & 25 & 18 & 23.1 & 22 & 30.1 & & \\
\hline Female & 54 & 75 & 60 & 76.9 & 51 & 69.9 & & \\
\hline \multicolumn{9}{|l|}{ Ethnicity } \\
\hline White British & 58 & 82.9 & 61 & 79.2 & 54 & 75 & 1.32 & 0.516 \\
\hline Other & 12 & 17.1 & 16 & 20.8 & 18 & 25 & & \\
\hline \multicolumn{9}{|l|}{ Region } \\
\hline East Anglia & 29 & 40.3 & 31 & 39.7 & 28 & 38.4 & 0.31 & 0.989 \\
\hline North London & 20 & 27.8 & 24 & 30.8 & 21 & 28.8 & & \\
\hline \multirow[t]{2}{*}{ North West } & 23 & 31.9 & 23 & 29.5 & 24 & 32.9 & & \\
\hline & Mean & SD & Mean & SD & Mean & SD & $\mathbf{F}$ & $\mathbf{p}$ \\
\hline Age & 15.57 & 1.44 & 15.61 & 1.34 & 15.43 & 1.49 & 0.39 & 0.720 \\
\hline MFQ baseline & 47.13 & 9.72 & 46.6 & 10.21 & 43.28 & 10.83 & 3.02 & 0.520 \\
\hline \multicolumn{9}{|c|}{ WAI-S-T sample ( $N=139)$} \\
\hline & \multicolumn{2}{|c|}{ BPI $(n=32)$} & \multicolumn{2}{|c|}{ CBT $(n=46)$} & \multicolumn{2}{|c|}{$\operatorname{STPP}(n=61)$} & & \\
\hline & $\mathbf{N}$ & $\%$ & $\mathbf{N}$ & $\%$ & $\mathbf{N}$ & $\%$ & Chi2 & $\mathbf{p}$ \\
\hline \multicolumn{9}{|l|}{ Gender } \\
\hline Male & 11 & 34.4 & 12 & 26.1 & 18 & 29.5 & 0.62 & 0.732 \\
\hline Female & 21 & 65.6 & 34 & 73.9 & 43 & 70.5 & & \\
\hline \multicolumn{9}{|l|}{ Ethnicity } \\
\hline White British & 22 & 68.8 & 30 & 65.2 & 44 & 76.6 & 1.14 & 0.573 \\
\hline Other & 10 & 31.3 & 16 & 34.8 & 15 & 25.4 & & \\
\hline \multicolumn{9}{|l|}{ Region } \\
\hline East Anglia & 14 & 43.8 & 14 & 30.4 & 32 & 52.5 & 8.35 & 0.080 \\
\hline North London & 18 & 56.3 & 28 & 60.9 & 24 & 34.3 & & \\
\hline \multirow[t]{2}{*}{ North West } & 0 & 0 & 4 & 8.7 & 5 & 8.2 & & \\
\hline & Mean & SD & Mean & SD & Mean & SD & $\mathbf{F}$ & $\mathbf{p}$ \\
\hline Age & 15.27 & 1.52 & 15.74 & 1.4 & 15.77 & 1.46 & 1.38 & 0.254 \\
\hline MFQ baseline & 45.73 & 11.62 & 46.8 & 11.12 & 46.3 & 9.53 & 0.09 & 0.162 \\
\hline
\end{tabular}

Note: MFQ=The Mood and Feelings Questionnaire 
Table 2. Descriptive Statistics

\begin{tabular}{ll|ccc|ccc}
\hline \multirow{2}{*}{ Variable } & Time & \multicolumn{3}{|c|}{$\begin{array}{c}\text { WAI-S sample } \\
\text { (n=223) }\end{array}$} & \multicolumn{3}{c}{ WAI-S-T sample } \\
(n=139)
\end{tabular}

Note: 0 = baseline assessment; $w=$ weeks after randomization; prior change $=$ changed occurred between 0 and 6 weeks. 
Table 3. Change in Depression (MFQ) and P factor as Predicted by the Alliance in the WAI-S sample with (Model 1) and without (Model 0) controlling for Prior symptom change and Baseline severity ( $N=223$ )

\begin{tabular}{|c|c|c|c|c|c|c|c|c|}
\hline \multirow{2}{*}{ Outcome: MFQ } & \multicolumn{4}{|c|}{ Model 0} & \multicolumn{4}{|c|}{ Model 1} \\
\hline & Estimate & SE & $\mathbf{p}$ & $95 \% \mathrm{CI}$ & Estimate & SE & $\mathbf{p}$ & $95 \% \mathrm{CI}$ \\
\hline \multicolumn{9}{|l|}{ Fixed effect } \\
\hline Intercept & 57.75 & 3.89 & 0.000 & $50.12 ; 65.37$ & 47.26 & 3.12 & 0.000 & $41.16 ; 53.35$ \\
\hline WAI-S: unstandardised & -0.25 & 0.05 & 0.000 & $-0.35 ;-0.14$ & -0.09 & 0.04 & 0.035 & $-0.17 ;-0.09$ \\
\hline$(W A I-S: \text { Effect size })^{a}$ & $(-0.39)$ & $(0.08)$ & $(0.000)$ & $(-0.56 ;-0.23)$ & $(-0.14)$ & $(0.06)$ & $(0.035)$ & $(-0.20 ;-0.01)$ \\
\hline Log Time & -4.57 & 0.49 & 0.000 & $-5.52 ;-3.61$ & -4.43 & 0.48 & 0.000 & $-5.36 ;-3.48$ \\
\hline CBT vs BPI & 1.22 & 1.98 & 0.540 & $-2.68 ; 5.11$ & 0.86 & 1.52 & 0.574 & $-2.14 ; 3.86$ \\
\hline CBT vs STPP & -4.58 & 2.12 & 0.033 & $-8.76 ;-0.39$ & -0.89 & 1.66 & 0.592 & $-4.16 ; 2.38$ \\
\hline Baseline severity & & & & & 0.72 & 0.07 & 0.000 & $0.57 ; 0.86$ \\
\hline Prior symptom change & & & & & 4.26 & 0.45 & 0.000 & $3.36 ; 5.14$ \\
\hline Random effect for level 2 (adolesc.) & \multicolumn{4}{|c|}{ SD } & \multicolumn{4}{|c|}{ SD } \\
\hline Intercept & \multicolumn{4}{|c|}{15.47} & \multicolumn{4}{|c|}{8.96} \\
\hline Log Time & \multicolumn{4}{|c|}{4.79} & \multicolumn{4}{|c|}{4.80} \\
\hline Residual & \multicolumn{4}{|c|}{8.27} & \multicolumn{4}{|c|}{8.33} \\
\hline Random effect for level 3 (therap.) & \multicolumn{4}{|c|}{ SD } & \multicolumn{4}{|c|}{ SD } \\
\hline intercept & \multicolumn{4}{|c|}{0.37} & \multicolumn{4}{|c|}{0.94} \\
\hline Outcome: $P$ factor & \multicolumn{4}{|c|}{ Model 0} & \multicolumn{4}{|c|}{ Model 1} \\
\hline Predictors & Estimate & SE & $\mathbf{p}$ & $95 \% \mathrm{CI}$ & Estimate & SE & $\mathbf{p}$ & $95 \% \mathrm{CI}$ \\
\hline \multicolumn{9}{|l|}{ Fixed effect } \\
\hline Intercept & 1.79 & 0.24 & 0.000 & $1.31 ; 2.26$ & 1.34 & 0.22 & 0.000 & $0.90 ; 1.78$ \\
\hline WAI-S: unstandardised & -0.02 & 0.00 & 0.000 & $-0.02 ;-0.01$ & -0.01 & 0.00 & 0.00385 & $-0.01 ;-0.00$ \\
\hline$(W A I-S: \text { Effect size })^{a}$ & $(-0.36)$ & $(0.07)$ & $(0.000)$ & $(-0.02 ;-0.01)$ & $(-0.20)$ & $(0.07)$ & $(0.004)$ & $(-0.30 ;-0.06)$ \\
\hline Log Time & -0.37 & 0.03 & 0.000 & $-0.43 ;-0.30$ & -0.37 & 0.03 & 0.000 & $-0.43 ;-0.30$ \\
\hline
\end{tabular}




\begin{tabular}{|c|c|c|c|c|c|c|c|c|}
\hline CBT vs BPI & 0.14 & 0.12 & 0.257 & $-0.10 ; 0.37$ & 0.12 & 0.11 & 0.263 & $-0.09 ; 0.33$ \\
\hline CBT vs STPP & -0.15 & 0.13 & 0.247 & $-0.40 ; 0.10$ & 0.00 & 0.12 & 0.970 & $-0.22 ; 0.23$ \\
\hline Baseline severity & & & & & 0.57 & 0.08 & 0.000 & $0.41 ; 0.72$ \\
\hline Prior symptom change & & & & & 2.69 & 0.50 & 0.000 & $1.70 ; 3.66$ \\
\hline Random effect for level 2 (adolesc.) & & & SD & & & SD & & \\
\hline Intercept & & & 0.81 & & & 0.31 & & \\
\hline Log Time & & & 0.35 & & & 0.26 & & \\
\hline Residual & & & 1.08 & & & 0.77 & & \\
\hline $\begin{array}{l}\text { Random effect for level } 3 \text { (therap.) } \\
\text { intercept }\end{array}$ & & & SD & & & SD & & \\
\hline
\end{tabular}

Note: $\mathrm{a}=$ standardised measure of the alliance-outcome association.

Table 4. Change in Depression (MFQ) and P factor as Predicted by the Alliance in the WAI-S-T sample with (Model 1) and without (Model 0) controlling for Prior symptom change and Baseline severity ( $N=139$ )

\begin{tabular}{|c|c|c|c|c|c|c|c|c|}
\hline \multirow{3}{*}{$\begin{array}{l}\text { Outcome: MFQ } \\
\text { Predictors } \\
\text { Fixed effect }\end{array}$} & \multicolumn{4}{|c|}{ Model 0} & \multicolumn{4}{|c|}{ Model 1} \\
\hline & Estimate & SE & $\mathbf{p}$ & $95 \% \mathrm{CI}$ & Estimate & SE & $\mathbf{p}$ & $95 \% \mathrm{CI}$ \\
\hline & & & & & & & & \\
\hline Intercept & 60.18 & 6.47 & 0.000 & $47.52 ; 72.83$ & 58.98 & 5.84 & 0.000 & $45.84 ; 67.34$ \\
\hline WAI-S-T: unstandardised & -0.27 & 0.10 & 0.010 & $-0.46 ;-0.07$ & -0.21 & 0.08 & 0.014 & $-0.38 ;-0.04$ \\
\hline$(W A I-S-T: \text { Effect size })^{a}$ & $(-0.30)$ & $(0.11)$ & $(0.010)$ & $(-0.52 ;-0.08)$ & $(-0.24)$ & $(0.09)$ & $(0.000)$ & $(-0.42 ;-0.05)$ \\
\hline Log Time & -5.17 & 0.57 & 0.000 & $-6.27 ;-4.05$ & -5.00 & 0.57 & 0.000 & $-6.10 ;-3.89$ \\
\hline CBT vs BPI & 2.61 & 2.93 & 0.376 & $-3.21 ; 8.44$ & 2.38 & 2.52 & 0.349 & $-2.62 ; 7.38$ \\
\hline CBT vs STPP & -1.43 & 2.63 & 0.590 & $-6.65 ; 3.80$ & -0.93 & 2.28 & 0.684 & $-5.46 ; 3.59$ \\
\hline Baseline severity & & & & & 0.61 & 0.10 & 0.000 & $0.41 ; 0.81$ \\
\hline Prior symptom change & & & & & 3.70 & 0.69 & 0.000 & $2.33 ; 5.06$ \\
\hline Random effect for level 2 (adolesc.) & & SD & & & & SD & & \\
\hline Intercept & & 11.68 & & & & 4.69 & & \\
\hline
\end{tabular}




\begin{tabular}{|c|c|c|c|c|c|c|c|c|}
\hline $\begin{array}{l}\text { Log Time } \\
\text { Residual }\end{array}$ & \multicolumn{4}{|c|}{3.53} & \multicolumn{4}{|c|}{3.61} \\
\hline $\begin{array}{l}\text { Random effect for level } 3 \text { (therap.) } \\
\text { intercept }\end{array}$ & \multicolumn{4}{|c|}{$\begin{array}{c}\text { SD } \\
2.07\end{array}$} & \multicolumn{4}{|c|}{$\begin{array}{c}\text { SD } \\
0.94\end{array}$} \\
\hline Outcome: P factor & \multicolumn{4}{|c|}{ Model 0} & \multicolumn{4}{|c|}{ Model 1} \\
\hline Predictors & Estimate & SE & $\mathbf{p}$ & $95 \% \mathrm{CI}$ & Estimate & SE & $\mathbf{p}$ & $95 \% \mathrm{CI}$ \\
\hline Fixed effect & & & & & & & & \\
\hline $\begin{array}{l}\text { Intercept } \\
\text { WAI-S-T: unstandardised }\end{array}$ & $\begin{array}{r}1.67 \\
-0.01\end{array}$ & 0.37 & 0.000 & $\begin{array}{l}0.94 ; 2.39 \\
-0.02 ; 2.54\end{array}$ & $\begin{array}{r}1.45 \\
-0.01\end{array}$ & & $\begin{array}{l}0.000 \\
0.125\end{array}$ & $\begin{array}{l}0.75 ; 2.15 \\
-0.49 ;-0.32\end{array}$ \\
\hline$(W A I-S-T: \text { Effect size })^{a}$ & $\begin{array}{r}-0.01 \\
(-0.18)\end{array}$ & $\begin{array}{r}0.01 \\
(0.09)\end{array}$ & $(0.052)$ & $(-0.36 ; 0.00)$ & $\begin{array}{l}-0.01 \\
(-0.14)\end{array}$ & $(0.09)$ & $\begin{array}{l}0.125 \\
(0.125)\end{array}$ & $(-0.31 ; 0.03)$ \\
\hline Log Time & -0.40 & 0.04 & 0.000 & $-0.48 ;-3.21$ & -0.41 & 0.04 & 0.000 & $-0.48 ;-0.32$ \\
\hline CBT vs BPI & 0.19 & 0.16 & 0.235 & $-0.12 ; 5.13$ & 0.25 & 0.15 & 0.114 & $-0.05 ; 0.55$ \\
\hline CBT vs STPP & -0.03 & 0.14 & 0.844 & $-0.31 ; 2.55$ & 0.03 & 0.14 & 0.835 & $-0.24 ; 0.29$ \\
\hline Baseline severity & & & & & 0.46 & 0.11 & 0.000 & $0.25 ; 0.66$ \\
\hline Prior symptom change & & & & & 0.98 & 0.53 & 0.068 & $-0.06 ; 2.03$ \\
\hline Random effect for level 2 (adolesc.) & & SD & & & & SD & & \\
\hline Intercept & & 0.30 & & & & 0.41 & & \\
\hline Log Time & & 0.22 & & & & 0.24 & & \\
\hline Residual & & 0.80 & & & & 0.79 & & \\
\hline $\begin{array}{l}\text { Random effect for level } 3 \text { (therap.) } \\
\text { intercept }\end{array}$ & & $\begin{array}{c}\text { SD } \\
0.02\end{array}$ & & & & $\begin{array}{c}\text { SD } \\
0.00\end{array}$ & & \\
\hline
\end{tabular}

Note: $\mathrm{a}=$ standardised measure of the alliance-outcome association.

Table 5. Treatment moderator analyses for the primary outcome (MFQ) as Predicted by Prior Depression Change, Baseline severity, treatment type and Alliance by Moderators Interactions

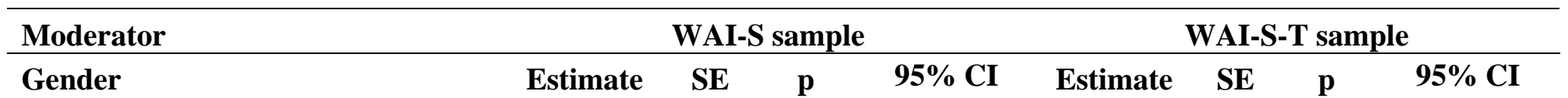




\begin{tabular}{lcccccccc} 
WAI-S X male vs female a & -0.01 & 0.15 & 0.931 & $-0.30 ; 0.28$ & 0.04 & 0.17 & 0.800 & $-0.28 ; 0.37$ \\
\hline Age & & & & & & & & \\
WAI-S X Age & -0.07 & 0.05 & 0.158 & $-0.15 ; 0.02$ & -0.06 & 0.07 & 0.392 & $-0.19 ; 0.07$ \\
\hline Baseline MFQ & & & & & & & & \\
WAI-S X Baseline severity & 0.00 & 0.00 & 0.930 & $-0.01 ; 0.01$ & 0.00 & 0.01 & 0.878 & $-0.02 ; 0.02$ \\
\hline ABQ & & & & & & & & \\
WAI-S X ABQ & -0.02 & 0.00 & 0.930 & $-0.06 ; 0.02$ & 0.02 & 0.02 & 0.394 & $-0.02 ; 0.06$ \\
\hline Treatment Arm & & & & & & & & \\
WAI-S X BPI vs CBT b & 0.45 & 0.19 & 0.018 & $0.07 ; 0.81$ & 0.49 & 0.24 & 0.041 & $0.02 ; 0.96$ \\
WAI-S X STPP vs CBT b & 0.16 & 0.16 & 0.326 & $-0.15 ; 0.48$ & 0.22 & 0.21 & 0.302 & $-0.19 ; 0.64$ \\
WAI-S X BPI vs STPP c & 0.29 & 0.15 & 0.064 & $-0.01 ; 0.58$ & 0.27 & 0.23 & 0.247 & $-0.18 ; 0.73$ \\
\hline
\end{tabular}

$a$ (Ref: female) b(Ref: CBT); c(Ref: STPP)

Table 6. Estimated effect of alliance on MFQ by treatment arm, adjusted for Prior Depression Change and Baseline Severity

\begin{tabular}{lcccccccc}
\hline Moderator & \multicolumn{4}{c}{ WAI-S sample } & \multicolumn{3}{c}{ WAI-S-T sample } \\
\hline Arm & Beta & SE & p & 95\% CI & Estimate & SE & p & 95\% CI \\
\hline CBT & -0.35 & 0.14 & 0.014 & $-0.62 ;-0.07$ & -0.44 & 0.15 & 0.004 & $-0.74 ; 0.14$ \\
STPP & -0.19 & 0.09 & 0.039 & $-0.36 ;-0.01$ & -0.22 & 0.15 & 0.136 & $-0.51 ; 0.06$ \\
BPI & 0.10 & 0.13 & 0.43 & $-0.15 ; 0.35$ & 0.05 & 0.18 & 0.786 & $-0.31 ; 0.41$ \\
\hline
\end{tabular}

